\title{
Heralding the New Publisher: Strategic Alliance and Improved Service
}

\author{
Joost Dekker $\cdot$ Redford B. Williams
}

Published online: 6 January 2009

(C) International Society of Behavioral Medicine 2008

As of 2009, International Journal of Behavioral Medicine $(I J B M)$ will be published by Springer Science + Business Media. Springer is one of the largest scientific, technical, and medical publishers in the world. It publishes over 1,750 journals in the fields of social and behavioral sciences, medicine, humanities, business and economics, engineering, mathematics, physics, and chemical sciences. Springer has experience in collaborating with academic and professional societies almost one fourth of the Springer journals are published on behalf of societies.

$I J B M$ and the International Society of Behavioral Medicine, as the owner of the journal, initiated the search for alternatives regarding journal publishers in 2007. ISBM member societies now number 20, representing over 5,000 individual members in North and South America, Europe, Asia, and Australia. ISBM is actively engaged in facilitating the formation of behavioral medicine societies in Africa. With the increasing awareness of the importance of taking a global perspective when it comes to improving health and the increasing awareness of the importance of behavioral factors in determining health not only in the first

\section{J. Dekker $(\square)$}

Department of Rehabilitation Medicine,

VU University Medical Center,

P.O. Box 7057, 1007 MB Amsterdam, The Netherlands

e-mail: j.dekker@vumc.nl

\section{J. Dekker}

International Journal of Behavioral Medicine,

VU University Medical Center,

P.O. Box 7057, 1007 MB Amsterdam, The Netherlands

\section{R. B. Williams}

International Society of Behavioral Medicine,

Duke University Medical Center,

Durham, NC, USA world but in developing countries also, IJBM is poised to reach an expanding global readership.

In searching for a new publisher, IJBM and ISBM realized that their strategic interests closely paralleled those of Springer. Springer's ambitions for global expansion match the strategic interests of IJBM and ISBM, enabling the strategic alliance of these organizations.

Negotiations with Springer have resulted in a markedly improved service level. Specifically, we would like to mention the following improvements:

- Free and easy electronic access of IJBM, as well as another Springer journal, to members of all ISBM Member Societies

- Discounted member price for individual members of Member Societies for the hard copy of IJBM

- Increased editorial page budget and a supplement of the bi-annual conference abstracts

- Online First: An article-based workflow that supports rapid online publication of individual articles prior to issue publication

- Open Choice: this is Springer's open-access option whereby, for a fee, authors may publish their article with permanent open access to all

- Web-based manuscript submission, review, and tracking system

- Significant support for the further development of $I J B M$, improved marketing of $I J B M$ and improved financial arrangements.

$I J B M$, as the official publication of the ISBM, offers the Society a platform for scientific discussions. The improved electronic access and the discounted member price facilitate the scientific discussions among members. Contributors, reviewers, and the team of (associate) editors will benefit from the web-based manuscript submission, review, and 
tracking system. Support for development and improved marketing will help IJBM to achieve its aims. Thus, for all parties involved, the new alliance with Springer is a big step forward.

IJBM uniquely publishes articles in three related fields (biobehavioral mechanisms, clinical care, and public health), contributing to a fruitful exchange of knowledge. A thorough understanding of biobehavioral mechanisms sharpens clinical and public health research. Insights derived from either clinical or public health studies naturally implicate the other. IJBM brings these differently focused but complementary domains together, not only to integrate knowledge but also to construct models of how the three fields can better work together to translate research findings into more effective approaches to prevention and treatment [1].

The present issue exemplifies the profile of IJBM. The special series on "Risk Perception, Behaviors and Pandemic Control in Emerging Infectious Diseases" addresses a highly relevant issue in global public health. The papers by Leppin and Aro [2], De Zwart et al. [3], Vartti et al. [4], Aro et al [5], Voeten et al. [6], and Jiang et al. [7] explore behavioral processes in pandemics of SARS, avian flu and other emerging infectious diseases. This research contributes to developing policies aiming to control future pandemics of emerging infectious diseases with a global reach. The papers by Bormann and Carrico [8] and Karsdorp et al. [9] address clinical care and biobehavioral mechanisms, respectively. The present issue is a good illustration of one of the defining characteristics of IJBM, i.e., the exchange of knowledge between the fields of biobehavioral mechanisms, clinical care, and public health.

We are confident that our new alliance with Springer will facilitate the future development of $I J B M$. The improved service level makes it easier for $I J B M$ to provide the global platform for the exchange of scientific knowledge on biobehavioral factors in health and disease and how to translate emerging knowledge in these areas into improved clinical care and public health.

\section{References}

1. Dekker J. Defining the profile. Int J Behav Med. 2007;14:1-2.

2. Leppin A, Aro AR. Risk perception related to SARS and avian influenza: theoretical foundations of current behavioral research. Int J Behav Med. 2009;16. doi:10.1007/s12529-008-9002-8.

3. De Zwart O, Veldhuijzen I, Elam G, Aro AR, Abraham T, Bishop GD, et al. Perceived threat, risk perception and efficacy beliefs related to SARS and other (emerging) infectious diseases: results of an international survey. Int J Behav Med. 2009;16. doi:10.1007/ s12529-008-9008-2.

4. Vartti AM, Oenema A, Schreck M, Uutela A, de Zwart O, Brug J, et al. SARS knowledge, perceptions and behaviors: a comparison between Finns and the Dutch during the SARS outbreak in 2003. Int J Behav Med. 2009;16. doi:10.1007/s12529-008-9004-6.

5. Aro AR, Vartti AM, Schreck M, Turtianen P, Uutela A. Willingness to take travel-related health risks: a study among Finnish tourists in Asia during the avian influenza outbreak. Int $\mathrm{J}$ Behav Med. 2009;16. doi:10.1007/s12529-008-9003-7.

6. Voeten HACM, de Zwart O, Veldhuijzen IK, Yuen C, Jiang X, Elam G, et al. Sources of information and health beliefs related to SARS and avian influenza among Chinese communities in the United Kongdom and the Netherlands, as compared to the general population in these countries. Int J Behav Med. 16. doi:10.1007/ s12529-008-9006-4.

7. Jiang X, Elam G, Yuen C, Voeten H, de Zwart O, Veldhuijzen I, et al. The perceived threat of SARS and its impact on precautionary actions and adverse consequences: a qualitative study among Chinese communities in the United Kingdom and the Netherlands. Int $\mathrm{J}$ Behav Med. 2009;16. doi:10.1007/s12529-008-9005-5.

8. Bormann JE, Carrico AW. Increases in positive reappraisal coping during a group-based mantram intervention mediate sustained reductions in anger in HIV-positive persons. Int J Behav Med. 2009;16. doi:10.1007/s12529-008-9007-3.

9. Karsdorp PA, Kindt M, Rietveld S, Everaerd W. False heart rate feedback and the perception of heart symptoms in patients with congenital heart disease and anxiety. Int J Behav Med. 2009;16. doi:10.1007/s12529-008-9001-9. 